\title{
Controls of Multiple Stressors on the Black Sea Fishery
}

\author{
Temel Oguz * \\ Institute of Marine Sciences, Middle East Technical University, Erdemli, Turkey
}

OPEN ACCESS

Edited by:

Sebastian Villasante, Universidade de Santiago de

Compostela, Spain

Reviewed by:

Brett W. Molony,

Department of Fisheries, Government

of Western Australia, Australia

Dimitrios K. Moutopoulos,

Technological Educational Institute of

Messolonghi, Greece

*Correspondence:

Temel Oguz

oguz@ims.metu.edu.tr

Specialty section:

This article was submitted to Marine Fisheries, Aquaculture and

Living Resources,

a section of the journal

Frontiers in Marine Science

Received: 25 January 2017 Accepted: 05 April 2017

Published: 25 April 2017

Citation:

Oguz T (2017) Controls of Multiple Stressors on the Black Sea Fishery.

Front. Mar. Sci. 4:110.

doi: 10.3389/fmars.2017.00110
Black Sea is one of the most severely degraded and exploited large marine ecosystems in the world. For the last 50 years after the depletion of large predatory fish stocks, anchovy (with the partial contribution of sprat) has been acting as the main top predator species and experienced a major stock collapse at the end of 1990s. After the collapse, eastern part of the southern Black Sea became the only region sustaining relatively high anchovy catch $(400,000$ tons) whereas the total catch within the rest of the sea was reduced to nearly its one-third. The lack of recovery of different fish stocks under a slow ecosystem rehabilitation may be attributed, on the one hand, to inappropriate management measures and the lack of harmonized fishery policy among the riparian countries. On the other hand, impacts of multiple stressors (eutrophication, alien species invasions, natural climatic variations) on the food web may contribute to resilience of the system toward its recovery. The overfishing/recovery problem therefore cannot be isolated from rehabilitation efforts devoted to the long-term chronic degradation of the food web structure, and alternative fishery-related management measures must be adopted as a part of a comprehensive ecosystem-based management strategy. The present study provides a data-driven ecosystem assessment, underlines the key environmental issues and threats, and points to the critical importance of holistic approach to resolve the fishery-ecosystem interactions. It also stresses the transboundary nature of the problem.

Keywords: Black Sea, climatic variability, ecosystem, fishery, multiple stressors

\section{INTRODUCTION}

At global scale, evidence is unequivocal for multitude of changes on ocean biogeochemical cycles and ecosystems due to ocean warming, acidification, and deoxygenation in response to the rising atmospheric $\mathrm{CO}_{2}$ levels (Hoegh-Guldberg and Bruno, 2010; Doney et al., 2012; Bopp et al., 2013; Poloczanska et al., 2013). Coastal, shelf, and semi-enclosed seas providing important economic resources experience additional stressors arising from the local/regional natural climatic variations, eutrophication, eutrophication-induced changes (such as acidification, de-oxygenation, loss of biodiversity, degradation of food web, etc), overfishing, and alien species invasion (Boldt et al., 2014). For these ecosystems, both $\mathrm{CO}_{2}$ and non- $\mathrm{CO}_{2}$ related stressors acting together have potential to alter trophic structure, food-web dynamics, energy and material flows, and biogeochemical cycles and thus impact considerably the ecosystem services for humans, as in the case of Baltic Sea (Niiranen et al., 2013; Jutterström et al., 2014). The Black Sea offers one of the best examples for how the multiple stressors act together to alter its ecosystem structure through regime shifts (Daskalov et al., 2007; Oguz and Gilbert, 2007; Oguz and Velikova, 2010; Llope et al., 2011; Akoglu et al., 2014).

The Black Sea is a nearly enclosed and zonally elongated basin with the zonal dimension of about $1,200 \mathrm{~km}$ and the meridional dimension varying from $500 \mathrm{~km}$ on the western side to $250 \mathrm{~km}$ 
toward the eastern side (Figure 1). It has a limited interaction with the Aegean Sea through the Turkish Straits System. Its main bathymetric feature is the presence of a narrow shelf (generally less than $20 \mathrm{~km}$ ) and steep topographic slope (generally less than $30 \mathrm{~km}$ ) around 2,000 $\mathrm{m}$ deep interior basin (Figure 1). The northwestern part of the sea characterized by a fairly wide shelf and its connection to the deep western basin through a wider topographic slope zone. The width of the western shelf gradually reduces toward south and finally terminates to the east of the Bosphorus Strait exit region (Figure 1). The Black Sea receives fresh water inflows all around the basin but the important ones discharge into the northwestern coastal waters. The River Danube being one of the largest rivers in Europe introduced dramatic effects on the Black Sea ecosystem.

The most recent in-depth ecosystem assessment has been provided by the State of the Environment Report published by the BSC (2009) and the fishery-specific assessment by FAO (2016). The present study complements them by providing a data-driven holistic ecosystem assessmentthat synthesizes the available data used for the BSC assessment, provides an overview picture on the transformations of the Black Sea ecosystem since the middle of the previous century, and describes the changes in fishery characteristics in harmony with the impacts of multiple environmental stressors. Gathering historical data and synthesizing existing knowledge may help to reconstruct historical baselines for understanding individual and cumulative impacts of disturbances on the ecosystem, especially over long(e.g., decadal) - time scales. The objective is to provide a scientific basis and justification for an implementation of ecosystem level management strategy to improve not only its fishery but also general health of the ecosystem as an alternative to the present approach of managing fish species independently.

Following the major characteristics features of climate variability and the past and present states of fishery, the present study describes the characteristic features of nutrient over enrichment and alien species invasions. Then, it describes the major changes in ecosystem state during the last 50 years. Finally, it identifies the major knowledge gaps in relation to ecosystemlevel management strategies (what to do and how to proceed forward) and gives the concluding remarks.

\section{MATERIALS AND METHODS}

The SST comprises monthly mean data compiled by Hadley Centre, UK Met Office (http://badc.nerc.ac.uk/data/hadisst). It consists of in situ measurements as well as Advanced Very High Resolution Radiation (AVHRR) satellite products (Rayner et al., 2003). The mean Cold Intermediate Layer (CIL) temperature data are given by Belokopytov (2011). This data set yields based on the monthly mean data constructed from all the available measurements performed within the interior part of the basin by averaging its values less than $8^{\circ} \mathrm{C}$. The yearly landing data on the basis of countries report were obtained from the Sea Around Us project (SAUP) database (http://www.seaaroundus. org). In the SAUP database the Soviet Union catches prior to 1990 comprised the sum of contributions from Ukrainian,
Georgian, and Russian catches. The same aggregation is also applied here after 1990 for representing the cumulative landing for the northern and eastern regions. Similarly, the Romanian and Bulgarian landings are aggregated for representing total fishery of the western region. The Turkish fleet was able to operate in Georgian waters after 1995 (Knudsen and Toje, 2008). Therefore, some of the catch realized in the Georgian EEZ is included in the Turkish landings statistics. Anchovy spawning stock biomass data after 1990 is taken from STECF (2015) whereas its earlier part is provided by Shlyakhov and Daskalov (2009). All the other data sets are provided by the Black Sea Commission data base that was used for the preparation of the State of the Environment Report (BSC, 2009) and may be made available to readers by the author up on request. Chlorophylla concentrations are retrieved from the monthly composite ocean color satellite data; the SeaWiFS sensor prior to 2002 (9 $\mathrm{km}$ resolution) and the MODIS sensor (4 $\mathrm{km}$ resolution) afterwards.

\section{CONTROL OF THE ECOSYSTEM BY INDIVIDUAL STRESSORS}

\section{Stressor 1: Climatic Variations}

The physical characteristics of the upper layer water column above the base of the permanent pycnocline experienced distinct decadal-scale oscillations (Oguz et al., 2006; Piotukh et al., 2011). The sea surface temperature (SST) is usedhere as a proxy for describing climatic variability. It indicates a relatively mild cooling phase $\left(0.5^{\circ} \mathrm{C}\right)$ during $1960-1980$ and a subsequent more pronounced cooling phase identified by the winter (DecemberMarch) mean sea surface temperature (SST) changes as high as $1.5^{\circ} \mathrm{C}$ during 1980-1993 (Figure 2). Similar variations are also observed in the summer-autumn (May-November) mean subsurface CIL temperature field (Figure 2). They are followed by an equally pronounced warming phase during 1993-2014. They imply a clear signal of climatic changes within the upper $100 \mathrm{~m}$ water column above the permanent pycnocline. The climate-induced temperature changes are related to strengthening of the NAO; its positive phase resulting in colder, drier, and more severe winters contrary to the simultaneous wetter, warmer, and milder winters over the northwestern Europe and the Eastern North Atlantic Ocean (Oguz et al., 2006). The subsequent warming trend starting by 1993 up to 2001 increases the SST and CIL temperature back to their former levels prior to the 1980. Afterwards, both SST and CIL temperature undergoes to a decadal scale oscillation with an amplitude of $\sim 1.5^{\circ} \mathrm{C}$ between the minimum at 2005-2006 and the maximum at 2010-2011, followed by a decreasing trend. The important point to note here is that such pronounced decadal scale temperature variations after 1980 match with the intensification of eutrophication and fishery and large population increase of the alien species Mnemiopsis leidyi. The temperature changes may introduce strong impacts on the Black Sea ecosystem through direct changes in species physiological characteristics and indirectly by the changes in the flow, stratification and mixing characteristics. 


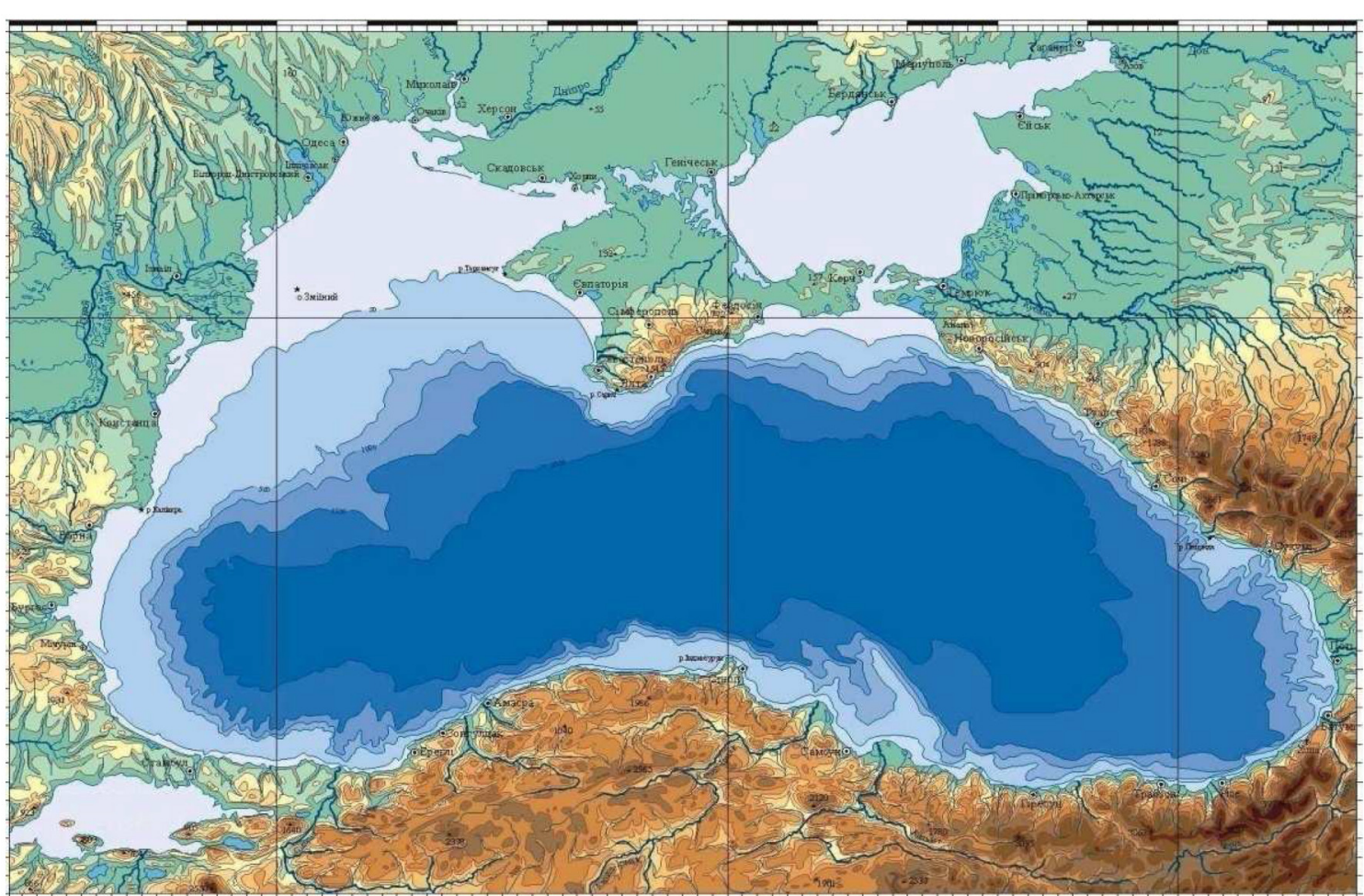

FIGURE 1 | The location and bathymetry of the Black Sea.

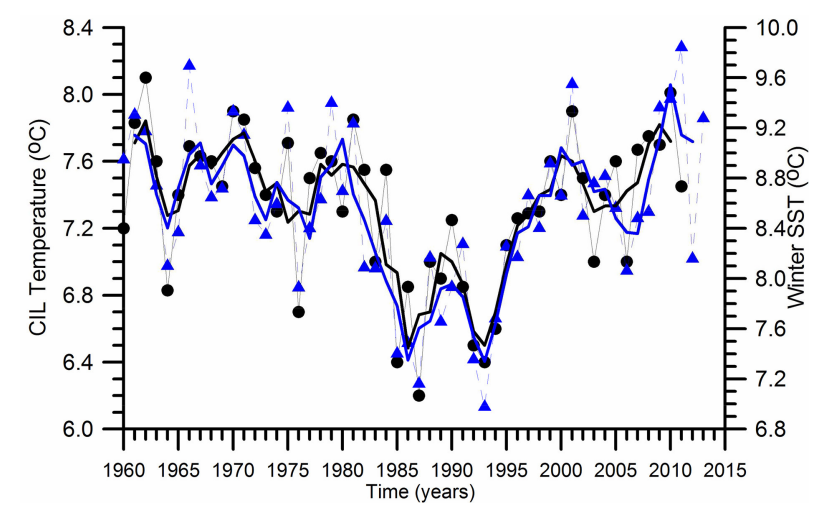

FIGURE 2 | Long term variations of the winter (December-March) mean sea surface temperature and the summer-autumn (May-November) mean Cold Intermediate Layer (CIL) temperature below the seasonal thermocline. The thin lines with symbols refer to the original data whereas the thick lines represent their smoothed variations by three point running averaged.

\section{Stressor 2: Fishery Overexploitation}

According to the long-term data (Figure 3A), the total fish landing reduces from $300 \mathrm{ktons}$ ( $1 \mathrm{kton}=1,000$ tons) to 100 ktons during the 1950s. The fish resources were exploited primarily by the former USSR (Georgia + Russia + Ukraine) as their total landing declined from more than 200 ktons to less than 50 ktons within a decade. The former USSR fishery first exploited the large and middle-size valuable predatory species including marine mammals, sturgeon, tuna, bonito, turbot, large horse mackerel, Black Sea mackerel prior to 1950s (Prodanov et al., 1997), and then started to exploit small pelagics with the Mean Trophic Level (MTL) index around 3.1-3.2 (Oguz et al., 2012a). On the other hand, the size of total Turkish landing was limited to $\sim 50$ kton level during the same period (Figure 3A), but the Turkish fishery primarily focused on the medium and large predatory fish groups identified by the MTL range between 3.4 and 3.8 (Oguz et al., 2012a). The Bulgarian+Romanian contribution to the total landing has always remained below 50 ktons (Figure 3A). The fishery, therefore, has been exploited severely in terms of the landing capacity, fish size, and diversity. As a result, the small pelagics became the only top predator group with a relatively low total landing size of 150 ktons over the entire basin toward the end of 1960s.

The total landings increased abruptly starting by the early 1970s to the range of 200-300 ktons within the former USSR countries and 500 ktons in Turkey. The October anchovy standing stock estimates (i.e., at the begining of the fishing season) increased drastically from $\sim 300$ ktons in the 1960s to 1.5 million tons in the late-1970s (Prodanov et al., 1997). A more conservative increase up to 700 ktons was suggested later by Shlyakhov and Daskalov (2009). Soon after the peak landing phase of the early1980s the USSR landing within the northnortheastern basin as well as the Romanian + Bulgarian landing within the western basin started declining gradually (Figure 3A). Nevertheless, the high level Turkish landing (around 500,000 


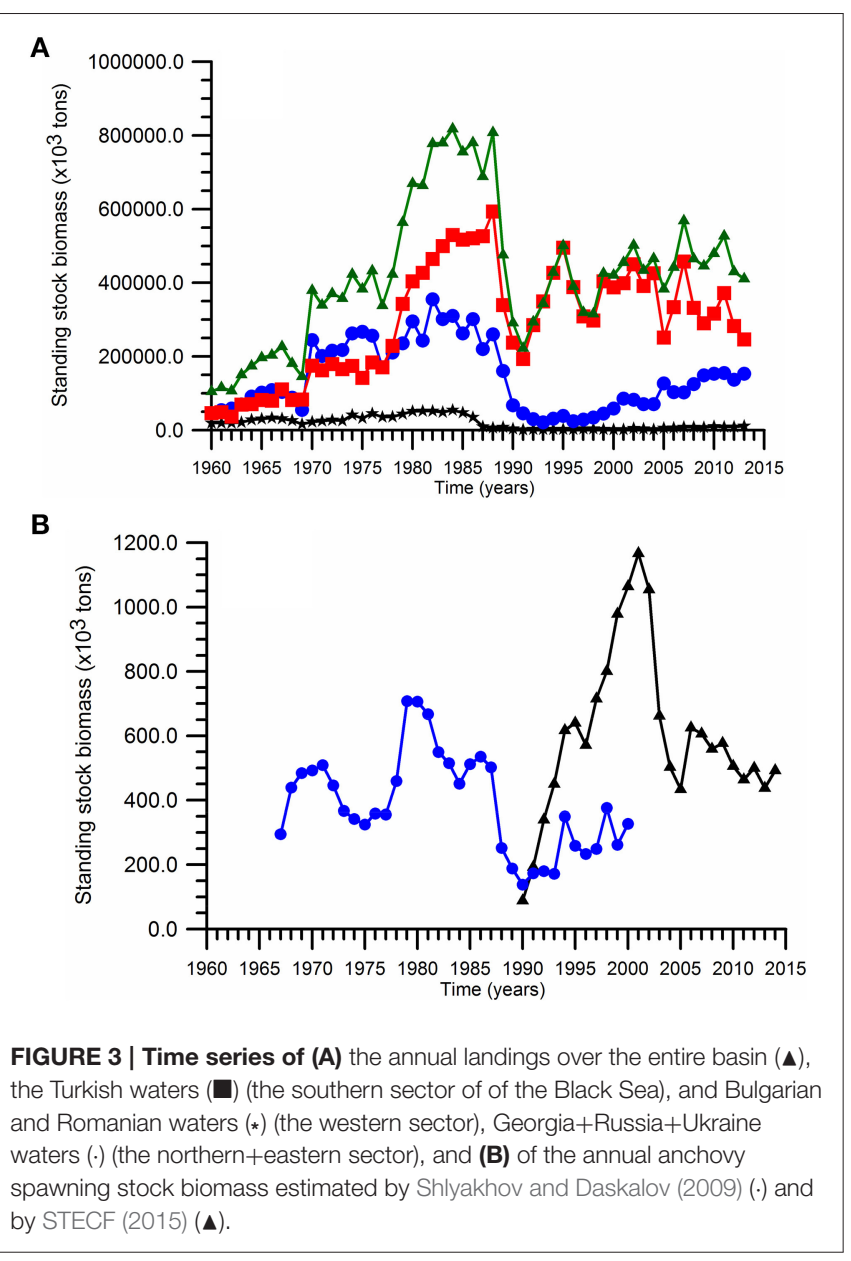

tons) within the southern basin was able to prevail until the end of 1980 s, after which it dropped abruptly to its minimum level of $\sim 200,000$ tons at 1990-1991 (Figure 3A). While this catch size was referred to as the collapse, it was in fact comparable to the maximum sustainable yield of the system (Oguz et al., 2012a). Afterwards, the former USSR landing remained around $10 \%$ level of their previous phase during the 1990s and increased up to 150 ktons subsequently, whereas the total western landing was negligibly low (Figure 3A). On the other hand, the Turkish exclusive economic zone was able to maintain the mean anchovy catch at $368,000( \pm 74,000)$ tons for $1992-2010$. This value was somewhat lower than the pre-collapse values but still comparable to twice of the maximum sustainable catch (Oguz et al., 2012a). The presence of oscillations in the landing data during this phase may likely indicate an unstable character of the Turkish fishery. The SAUP data base also provides an alternative catch data by the inclusion of unreported catch estimates. This alternative data set suggests $100 \%$ percent difference between the reported and actual amounts of fish caught and the overall catch then amounts to $\sim 800,000$ tons after 1995 . The catch size during the last two decades is comparable to that given for the transitional period of the 1970s between the pre- and intense-eutrophication phases. But they differ in terms of spatial catch distributions.

\section{Stressor 3: Nutrient Overenrichment}

Substantial increase in nutrient concentrations of the upper layer water column throughout the sea was a striking feature of the Black Sea ecosystem in the 1970s and the early-1980s. These changes were caused by the implemention of a massive fertilizer consumption in agriculture in the former Soviet Union and Warsow Pact countries to compensate the food loss due to the collapse of fishery (Mee, 2006). This led to an increase in the total nitrogen (phosphorus) emission in the River Danube catchment basin from about 400 (40) $\mathrm{kt} \mathrm{yr}^{-1}$ in the 1950s to $900(>100) \mathrm{kt}$ $\mathrm{yr}^{-1}$ in the 1980s.

Approximately $80 \%$ of the total anthropogenic nitrogen flux was supplied by the River Danube whereas the rest was provided by the rivers discharging along the northwestern coast (Dniepr, Dniester, Bug) and along the southern coast (Figure 1). However, due to the lack of systematic nutrient measurements at the Danube discharge sections during the 1970s and the early 1980 s, it was not possible to monitor precisely the magnitude of anthropogenic-based nutrient enrichment during its initial phase. Nevertheless, the scattered measurements performed near the Chilia discharge point of the River Danube (at Vilkova) indicated an average DIN concentration of $56.6 \mu \mathrm{M}$ for 19481960 (the pre-eutrophication phase), increasing subsequently to $118.9 \mu \mathrm{M}$ in $1977-1985$ and $156.1 \mu \mathrm{M}$ in $1989-1992$. The latter was roughly half of the mean DIN value of $310 \mu \mathrm{M}$ measured at the Sulina discharge point during the same period in addition to a drastic rise of DON concentration from $\sim 50$ to $\sim 350 \mu \mathrm{M}$. Consequently, the sum of organic and inorganic dissolved nitrogen concentration at the end 1980s reached 500 $\mu \mathrm{M}$ that implies a nearly five-fold increase with respect to the pre-eutrophication conditions. A similar increase was also noted within the Romanian and Ukranian sectors of the northwestern shelf during the 1970s with the annual mean surface nitrate and phosphate concentrations more than 20 and $3 \mu \mathrm{M}$, respectively (Figure 4A).

Following the collapse of centrally-planned economy within the former Soviet Union, nitrogen and phosphorus fertilizer consumptions reduced to 1.5 and $0.5 \mathrm{mt} \mathrm{yr}^{-1}$, respectively, during the early 1990s (Mee, 2006). With the additional contributions by the closure of ecologically ineffective large animal farms (agricultural sources) and the introduction of phosphorus-free detergents and the improved nutrient removals at treatment plants, the Danube $\mathrm{P}-\mathrm{PO}_{4}$ load reduced sharply from $\sim 30 \mathrm{kt} \mathrm{yr}^{-1}$ to about $10 \mathrm{kt} \mathrm{yr}^{-1}$ (Figure 4B). The decrease in the Danube DIN load was more substantial; from around $700 \mathrm{kt}$ $\mathrm{yr}^{-1}$ to less than $200 \mathrm{kt} \mathrm{yr}^{-1}$ (Figure 4B). 90\% of the DIN load was provided by $\mathrm{N}-\mathrm{NO}_{3}$. They resulted in nitrate and phosphate concentrations less than 5 and $0.5 \mu \mathrm{M}$, respectively, within the shelf. DON concentrations, on the other hand, preserved its former high levels. The nutrient fluxes from the Dniepr and Dniestr Rivers into the NWS are an order of magnitude smaller during both the intense and post eutrophication phases, and introduce only local effects in the vicinity of their discharge regions.

Benthic nutrient fluxes were found to be particularly high in the vicinity of discharge zones, but decreased almost by an order of magnitude toward the shelf edge depending on intensity of 

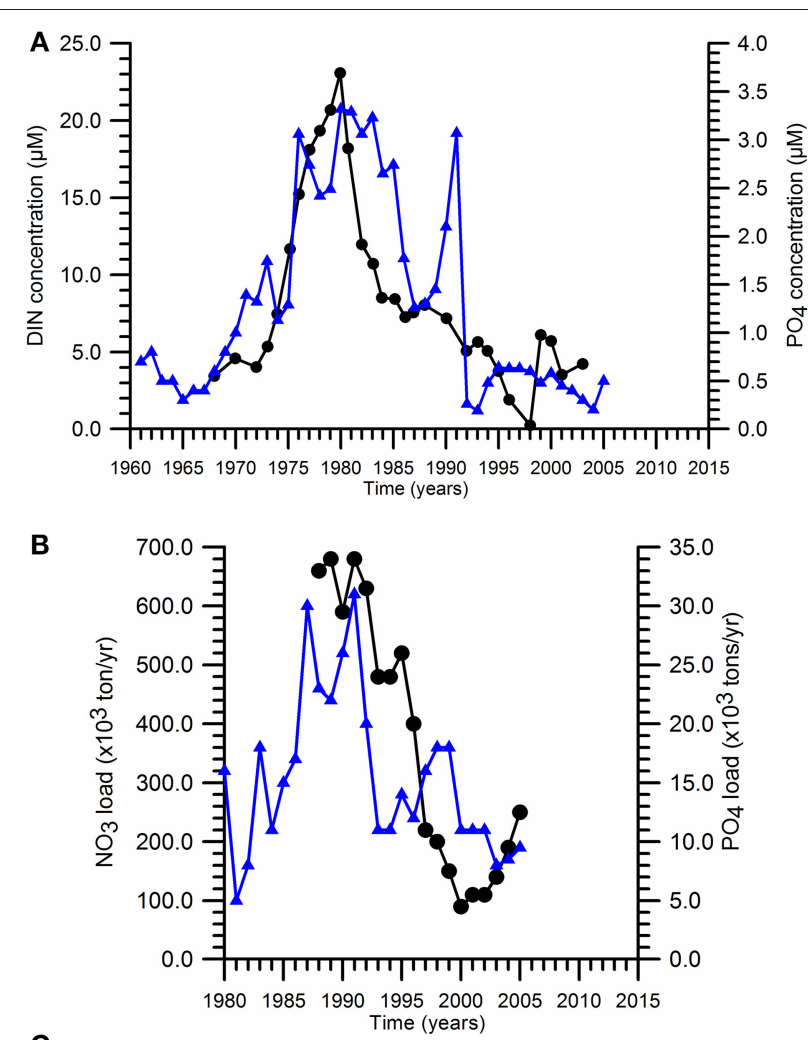

C

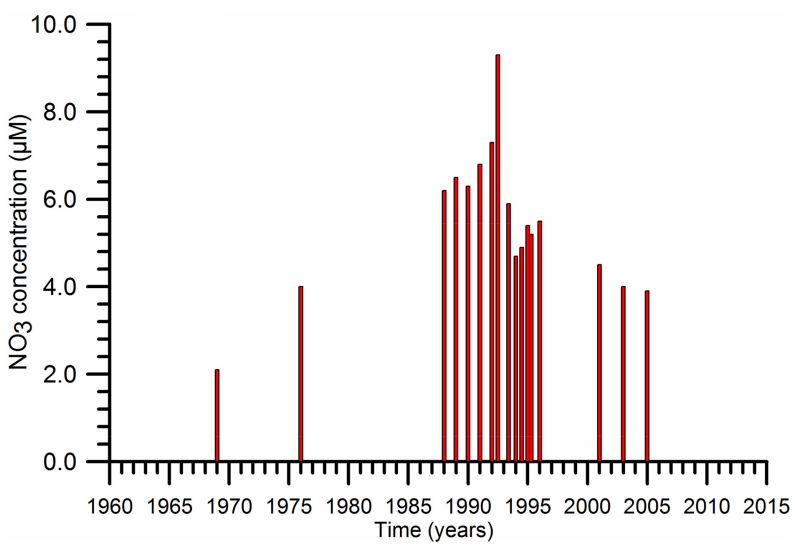

FIGURE 4 | Temporal variations of (A) the annual mean surface nitrate ( and phosphate $(\bullet)$ concentrations within the northwestern (Romanian and Ukranian sectors) coastal-inner shelf waters, (B) River Danube annual dissolved inorganic nitrogen (DIN) and phosphate (P-PO4) loads, (C) maximum nitrate concentrations measured at the chemocline of interior deep basin.

primary production, vertical mixing, and water depth (Gregoire and Friedrich, 2004). The estimate of total ammonium flux of 250 ktons $\mathrm{yr}^{-1}$ turns out to be higher than the post-eutrophication value of the River Danube DIN flux. Similarly, the corresponding

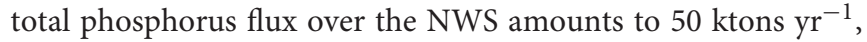
which is also much higher than that provided by the River Danube. The sediment data, therefore, imply that the benthic system still keeps the memory of past eutrophication and the benthic nutrient recycling mechanism constitutes an important factor for sustaining high productivity especially in shallower parts of the NWS.

The additional nutrient inputs from the atmospheric wet and dry depositions are not known precisely, but the estimated

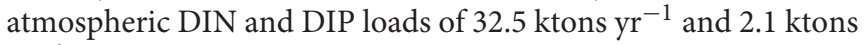
$\mathrm{yr}^{-1}$, respectively, are much smaller than the corresponding riverine loads over the annual time scale (Medinets and Medinets, 2012). Nevertheless, episodic high deposition events into nutrient depleted surface waters during late spring-summer may occasionally prevail over the basin. The model estimated atmospheric nutrient inputs were, on the other hand, much lower and less than $10 \%$ of the river inputs (cited by Artioli et al., 2008).

The basinwide response of increased nutrient supply by the northwestern rivers after the early 1970s was their accumulation within the chemocline zone of the upper layer as suggested by the rise of the subsurface nitrate peak from roughly $2-3 \mu \mathrm{M}$ prior to the enrichment phase to $6-8 \mu \mathrm{M}$ afterwards over the entire basin (Figure 4C). As the increased nutrient supply built up nutrients more effectively in the chemocline zone (located immediately below the euphotic layer), these nutrients were made available to the euphotic layer more effectively under strong winter climatic conditions. This peak was slightly eroded after 1990s and reduced to $4-5 \mu \mathrm{M}$ in response to the reduction in anthropogenicbased nutrient reduction loads. A similar structure continues to maintain today (Tugrul et al., 2014).

\section{Stressor 4: Invasion by Alien Gelatinous Species}

As the environmental deterioration progressed in the Black Sea, opportunistic, and gelatinous species started dominating the food web (Kovalev and Piontkovski, 1998). The jellyfish Aurelia aurita being less than $50 \mathrm{~g} \mathrm{~m}^{-2}$ before the $1960 \mathrm{~s}$ became a major gelatinous predator species during the eutrophic ecosystem of early-1980s with typical biomass around $500 \mathrm{~g} \mathrm{~m}^{-2}$ and then declined to $100 \mathrm{~g} \mathrm{~m}^{-2}$ toward the end of 1980s (Figure 5A). The increase in Aurelia biomass might have been associated with the overfishing and removal of mackarel, which was a main predator of Aurelia in Black Sea (Arai, 2001). Following the massive population increase of M. leidyi at the end of 1980s, the Aurelia biomass became comparable to the pre-eutrophication phase, because of better competitive advantage of Mnemiopsis consuming preys.

Following its accidental introduction into the Black Sea from its native habitat along the eastern coastal waters of the North and South America continents in the early 1980s (Purcell et al., 2001), Mnemiopsis was observed in different parts of the Black Sea during 1982-1987. Its average biomass reached 1 $\mathrm{gC} \mathrm{m}^{-2}\left(\approx 1.0 \mathrm{~kg} \mathrm{ww} \mathrm{m} \mathrm{m}^{-2}\right.$ ) during summer-autumn $1988 \mathrm{in}$ the eastern basin (Shiganova et al., 2014), and then suddenly acquired an outbreak with the biomass level up to $\sim 3.0 \mathrm{gC}$ $\mathrm{m}^{-2}$ in coastal waters during 1989-1990 (Figure 5A). Soon after the population outburst phase (1988-1992), Mnemiopsis abundance and biomass stabilized at lower levels, but acted as the main predator on the food web structure. Its impact on the fodder zooplankton is 3-4 fold reduction in its biomass (Figure 5A). 

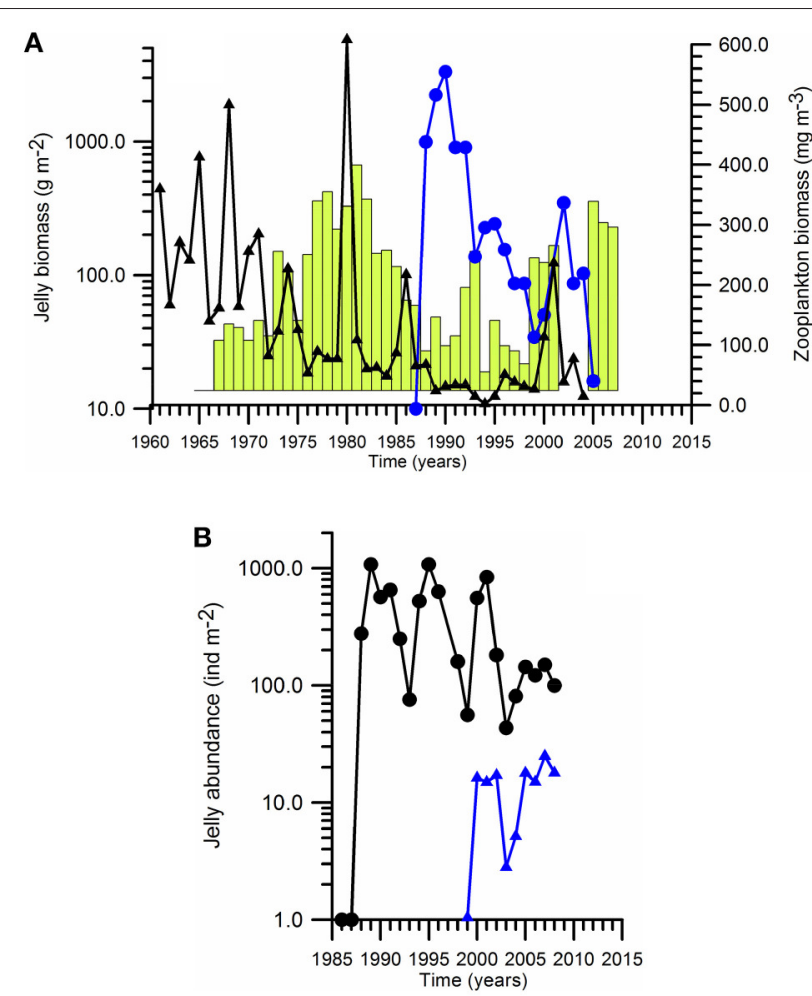

FIGURE 5 | Long-term biomass changes of (A) Aurelia biomass (vertical bars), Mnemiopsis biomass ( $\bullet$ ) and edible zooplankton biomass ( $\mathbf{\Lambda})$, and (B) Mnemiopsis abundance in August $(\bullet)$ and Beroe abundance in September ( in the northeastern shelf-slope region.

The ctenophore species Beroe ovata entered accidentally at 1998 and started predating on Mnemiopsis population and reducing its biomass and abundance (Figure 5B). Starting by 1999, Mnemiopsis biomass was reduced considerably except the late summer-autumn at its peak reproduction phase (Vinogradov et al., 2000). Nevertheless, M. leidyi can be still observed at high concentrations in the northwestern and western coastal regions with respect to its lower abundance elsewhere. As a result, the predation pressure of Mnemiopsis on zooplankton became limited to the late-summer and autumn months. The nich vacated by Mnemiopsis was, then, occupied by an increase in the jellyfish Aurelia biomass to the range of $200-500 \mathrm{~g} \mathrm{~m}^{-2}$ (Figure 5A). The other gelatinous species Pleurobrachia has never played a predominant role on the food web structure. As a matter of fact, the present reduced jelly biomass/abundance is still higher than the corresponding values in the Mediterranean and Baltic Seas. Among the 63 LMEs, the Black Sea attains the highest Jellyfish Index value which is twice higher than the values of other European Seas (Brotz et al., 2012).

\section{Stressor 5: Frontal and Mesoscale Circulation Features}

Gucu et al. (2016) recently noted a non-migratingcharacter of the anchovy stocks within the southern Black Sea that utilized local food resources confined within coastal hydrographic features associated with the rim current. In fact, the narrow peripheral zone of the Black Sea appears to be always more productive at all trophic levels than the interior basin. The field observations performed in the northeastern Black Sea (i.e., almost 1,000 $\mathrm{km}$ away from the main source of eutrophication) documented relatively high concentrations of phytoplankton and zooplankton species/groups within the shelf-slope zone with respect to further offshore (Vinogradov et al., 2011; Mikaelyan et al., 2013; Arashkevich et al., 2014; Shiganova et al., 2014, and others). The fish eggs and larvae surveys (Niermann et al., 1994; Kideys et al., 1999; Gucu et al., 2016) and abundance and biomass measurements of gelatinous species (Mutlu, 2009) along the southern Black Sea showed their patchy distributions with higher concentrations closer to the coast. The primary production required (i.e., ecological cost of the catch) in this region was also found to be roughly twice of its basin-averaged maximum sustainable value (Oguz et al., 2012a) indicating higher phytoplankton production with respect to the interior basin. Furthermore, the annual mean surface chlorophyll-a (Chl-a) concentrations around the basin, provided by the satellite ocean color data, always exceeded those of the interior with some interannual variability (Figure 6A).

The mechanisms promoting relatively high phytoplankton population and thus supporting more effective zooplankton, small pelagics fish, and larvae populations around the periphery with respect to the cyclonic domes of the interior basin remained unexplained quantitatively to date. The nutrient enrichment from the rivers around the basin alone appears to be too low to maintain such a persistent basinwide feature except the Northwestern shelf. The recent modeling study by Oguz (submitted) relates this feature to the frontogenesis mechanism of the Rim Current circulation arising from its nonlinearity and collapse of the along-front geostrophic balance (Mahadevan, 2016). The resulting ageostrophic cross-frontal vertical circulation cell then provides high vertical velocities $\left(\sim 10-50 \mathrm{~m} \mathrm{~d}^{-1}\right)$ at meander crests on the less dense coastal anticyclonic sides of the front. They supply nutrients effectively into the euphotic zone relative to the cyclonic offshore side and to produce locally high plankton biomass. The transports of biota and nutrients by the rim current around the basin and offshore into the interior cyclonic cell by mesoscale features then sustain a year around relatively high phytoplankton biomass around the basin (Figure 6B). The eddy-induced horizontal and vertical nutrient transports and diapycnal turbulent mixing further contribute to the enhancement of plankton production.

\section{CUMULATIVE EFFECTS OF MULTIPLE STRESSORS ON THE ECOSYSTEM AND FISHERY}

The Black Sea ecosystem experienced three alternative states. The "pre-eutrophication" state prior to the early 1970s represented relatively mild winters, low anthropogenic loads from rivers, a modest level of phytoplankton biomass, weakening of their topdown pressure due to the loss of piscivours, and over-exploitation of its fishery resources. The transition toward the development of 


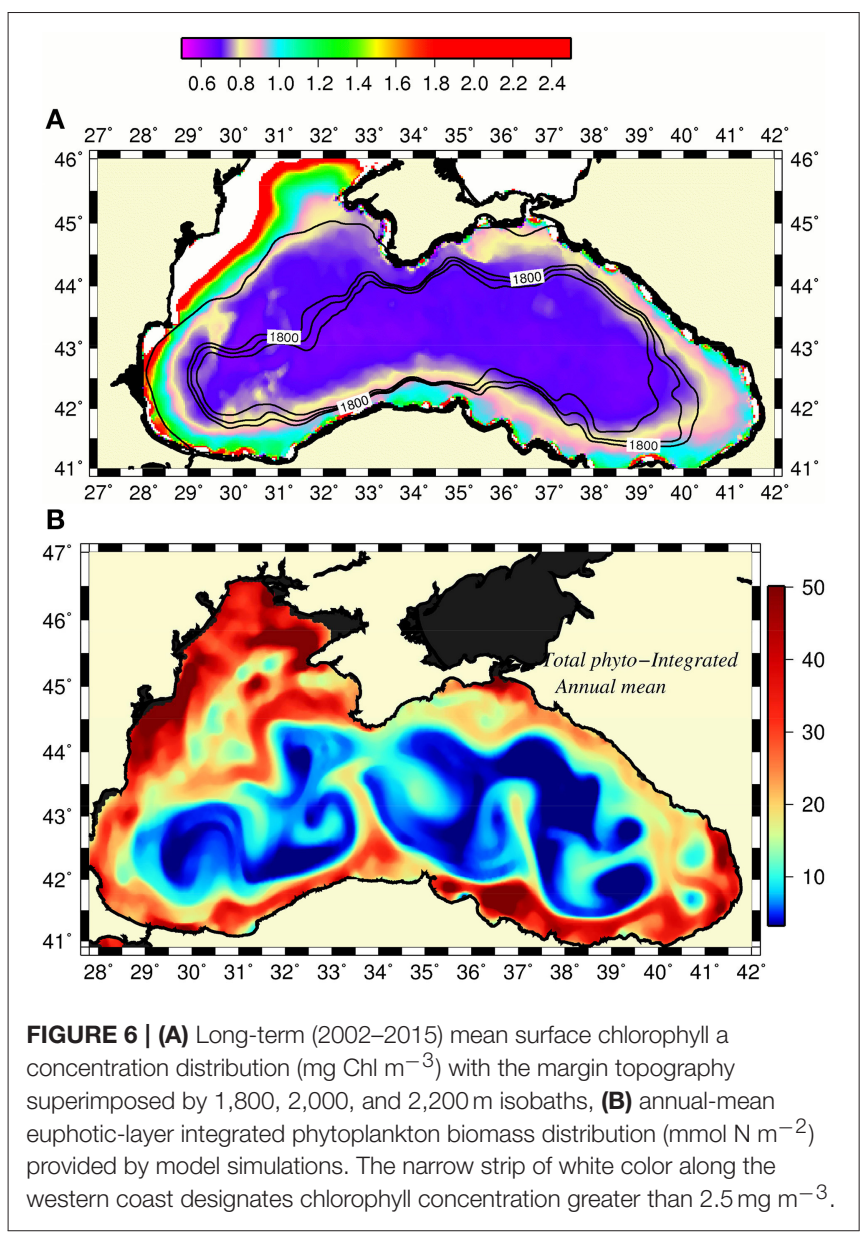

more productive "intense eutrophication" state during the 1970s (the first regime shift) was accomplished by the loss of predator controls and over-enrichment of the upper layer water column due to eutrophication and climate-induced cooling. The period after the early 1990s constitutes the "post-eutrophication" state.

\section{Intense Eutrophication State}

Three-four fold increase of the chemocline layer nitrate concentrations over the entire Black Sea during the decadal climatic cooling phase (i.e., more severe winter climatic conditions) increased phytoplankton biomass up to 10 -folds within the northwestern shelf and the interior basin during the 1980s. The euphotic zone-integrated mean phytoplankton biomass within the central and eastern basins during summerautumn increased from about $2-3 \mathrm{~g} \mathrm{~m}^{-2}$ before $1970 \mathrm{~s}$ to $10 \mathrm{~g}$ $\mathrm{m}^{-2}$ in the 1970s and $20 \mathrm{~g} \mathrm{~m}^{-2}$ in the 1980s (Figure 7A). Cold winters imply greater vertical turbulent and advective fluxes of nutrients into the euphotic zone from the subsurface waters that then may support stronger spring and subsequent summer blooms. These features may explain the cause of relatively high surface phytoplankton biomass $\left(>10 \mathrm{~g} \mathrm{~m}^{-3}\right)$ maintained throughout the 1980s and the early 1990s over the Ukrainian, Romanian and Bulgarian shelf waters. The deep interior basin was also exposed to a similar increase in phytoplankton biomass.

One of the critical features of the eutrophic Black Sea during the 1980s has been the development of a complementary food chain toward the dead-end opportunistic species (e.g., Noctiluca scintillans) and jellyfish in addition to the classical pathway toward small pelagics. Because they were more competitive on grazing of zooplankton, they were able to divert more energy from the system and thus limiting the efficiency of the classical food web. For example, the biomass of heterotrophic dinoflagellate species Noctiluca, as a voracious predator with diverse diet including a wide range of phytoplankton, bacteria, detritus, eggs, and naupliar stages of copepods was increased along the western coastal waters by an order of magnitude roughly from $100 \mathrm{mg} \mathrm{m}^{-3}$ in the 1970 s to about $1,000 \mathrm{mg} \mathrm{m}^{-3}$ in the 1980s (Figure 7B).

The Black Sea ecosystem produced higher edible zooplankton biomass during the eutrophic phase of 1980s with respect to the pre-eutrophication phase. But, its biomass in the northwestern shelf declined steadily later in the 1980s with (Figure 5A) due to heavier predation by small pelagics and gelatinous carnivores and replacement by smaller and less valuable species due to degradation of the food web structure. The edible zooplankton biomass within the eastern basin did not show any particular trend; instead it fluctuated within the range of $5-15 \mathrm{~g} \mathrm{~m}^{-2}$ during the same period (Figure 7A).

The ecosystem state experienced the second regime shift a decade later. It was characterized by the collapse of small pelagic fish stocks due to their over-harvesting and simultaneous impact of population outburst of the gelatinous carnivorous M. leidyi at the end of 1980s. As substantiated by the modeling studies (Oguz et al., 2008), the simultaneous anchovy collapse and Mnemiopsis outburst was possible in the eutrophic ecosystems under favorable climatic conditions promoting excessive nutrient enrichment of the euphotic layer from the chemocline. Beyond its a particular limit, the nutrient flux starts supporting more favorably the growth of gelatinous populations instead of its competitor fish species. Physiologically, a growth and reproduction advantage of Mnemiopsis relative to the native gelatinous species Aurelia, and advantage of food consumption in respect to anchovy promote its growth excessively without saturation. Therefore, their stronger predation pressure on anchovy eggs and larvae caused reduction in anchovy recruitment biomass and weakening its competition against Mnemiopsis. These mechanisms together with high anchovy harvesting inevitably caused recruitment failure and the stock collapse of anchovy. Akoglu et al. (2014) also pointed to the synergistic roles of resource competition and fishery exploitation for the anchovy-Mnemiopsis regime shift using an indicatorbased mass balance food web analyses. An important implication of these modeling studies is to link the anchovy collapse to the Mnemiopsis population under the conditions of high nutrient enrichment of the system. This mechanism opposes to the alternative view that, based on subjective grounds from the catch data, links the fishery collapse solely to their overexploitation. It also opposes to another hypothesis that relates the catch decline not to the collapse of stocks but their translation, for some 


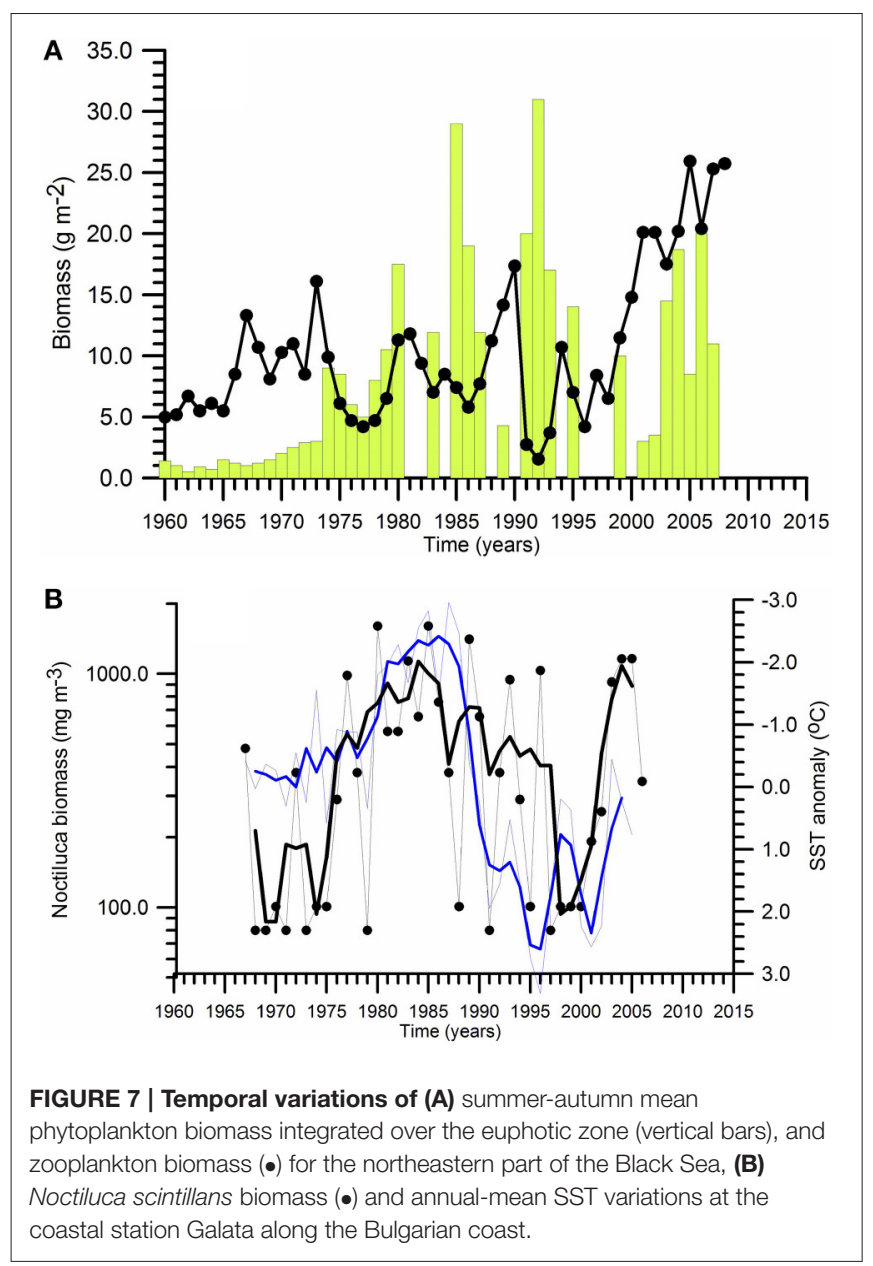

unknown reasons, away from their regular fishing grounds (Gucu et al., 2017).

\section{Post-eutrophication State}

Starting by the early 1990s, the last two decades are referred to as the "post-eutrophication" state characterized by the decreasing nutrient loads and nitrate accumulation at the chemocline zone, the climatic warming trend, and the absence of fishery except in the southern basin. In the early years of the posteutrophication phase (i.e., the 1990s) Mnemiopsis introduced a major stress on the food web and acted as the major top predator in many regions in the absence of small pelagic stocks. The phytoplankton and Noctiluca biomass also decreased during the post-eutrophication phase in aggrement with the reduced antropogenic nutrient supply and negative effect of climatic warming conditions (Figures 7A,B). The reduced top-down and bottom-up controls might have altered food web functioning the details of which is not exactly known due to the lack of systematic observations.

By the introduction of $B$. ovata to the Black Sea at the end of 1990 s, the predation pressure of Mnemiopsis became limited to the autumn period, and the reduction in its biomass turned out as an increase in the catch data, as noted by its twice higher USSR values for the northern-northeastern basin (Figure 3A). On the other hand, the absence of any increase on the catch data within the western part may be related to the ongoing strong Mnemiopsis control.

An important feature of the post-eutrophicatipon phase is the shift of the annual phytoplankton bloom structure from its former double-peak form (a relatively strong March-April peak and a secondary peak in November-December) prevailed during the intense eutrophication phase under severe winters to a single-peak form encompassing November-February period but more predominantly during November-December (Figure 8). The cause of this shift is not known so far but the persistence of relatively warm climatic regime and a change in the predatory control after the introduction of Beroe may contribute to it. Another notable feature is higher annual mean chlorophyll concentrations and stronger winter peaks during warm years and vise versa for cold years (Figure 8). This feature was explained by a more limited offshore spreading of productive coastal waters toward the interior basin during cold years due to the intensification of the rim current circulation and weakening of its mesoscale variability (Kubryakov et al., 2016). On the contrary, more intense mesoscale variability of the rim current circulation in mild years may promote stronger bottom-up food supply to higher trophic levels and support higher anchovy stock biomass as compared to those in cold years. This assertion, however, needs to be quantified by biophysical modeling studies. The climate impact on phytoplankton biomass is also depicted on the interior basin phytoplankton biomass variations in the form of a declining trend during the warming phase of the 1990s and increasing trend during the subsequent cooling phase (Figure 7A).

The main ecosystem properties appear to differ considerably between the western, southern, and northeastern regions (Oguz et al., 2012b). The pelagic food web structure of the western shelf represents worst ecological conditions dominated by the absence of forage fish stocks and the persistence of relatively strong Mnemiopsis and Noctiluca predation controls. As the jellies and planktivorous fish group were the competitors for feeding on trophic zooplankton, the post-eutrophication state appears to be more strongly controlled by the undesirable jelly-dominated system. On the other hand, the impacts of opportunistic and gelatinous species were less critical in the northeastern and the southern Black Sea, but the northeastern region continued to be depleted by forage fish stocks.

The anchovy spawing stock biomass estimates for 1967-2000 provided by Shlyakhov and Daskalov (2009) and the more recent one for 1990-2014 by STECF (2015) are markedly different (Figure 3B). While the stock does no exceed $400 \mathrm{ktons}$ in the former estimate, the more recent one provided an increasing trend up to 1,200 ktons during the 1990s, and declined abruptly afterwards below 600 ktons in 2005. However, it is hard to accept the realism of such a drastic increase in the fish stocks during the period of maximum predation impact of Mnemiopsis in the ecosystem. Nevertheles, its is interesting to note that its temporal changes follow closely those of SST and CIL temperature depicted earlier in Figure 2. Apparently, being a warm water species, cold years are expected to be unfavorable for anchovy growth as indicated by the declining trend of the parental anchovy stocks 


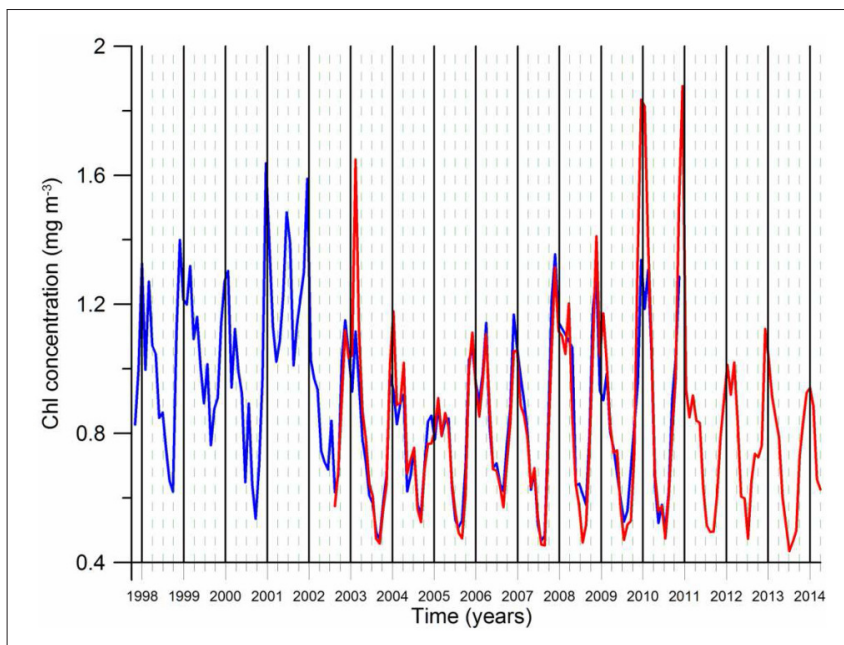

FIGURE 8 | The monthly-mean chlorophyll-a concentration variation of the post-eutrophication phase (1998-2013) averaged for the region $30-41^{\circ} \mathrm{E}$ longitude and $41-45^{\circ} \mathrm{N}$ latitude. The data are retrieved from the SeaWiFS (blue) and the MODIS (red) ocean coor sensor.

during the cold years of 1980s and the first half of 2000s contrary to a strong increasing trend during warming years of 1990s. Of course, the climatic pattern is modulated simultaneously to some extent by the non-climatic factors (e.g., fishery over-exploitation, outburst of Mnemopsis population).

\section{The Present State of Fishery}

At present, the Black Sea is devoid of predatory fish species, and roughly $85 \%$ of the total fish catch comprises the low cost anchovy and it is limited mostly to the southeastern region. It represents globally one of the worst case situations in terms of inappropriate management policy causing such a drastic collapse. The fleet overcapacity, mostly the Turkish one, causes to catch more fish than its sustainable level and above the quotas through illegal or unreported catches. The quotas have been and are still enforced under political and social pressures to support short-term fishing prospects instead of the long-term sustainability, as many subsidies in the fisheries sector foster overcapacity and overexploitation of fish stocks. Complexity of pressures introduced by multiple stressors (eutrophication, alien species invasions, natural climatic variations) on the food web functioning further exacerbates the situation. As elaborated by the analysis given above, the distinction of this overfishing/recovery problem is its intimate link to the simultaneous severe degradation of the lower trophic level food web. Therefore, in the Black Sea, the fight for recovery is much more challenging and needs going along with rehabilitation measures of the ecosystem structure. It therefore differs substantially from the overfishing problem of an ecologically undegraded (or much less degraded) system, for which the main target of maintaining sustainable fishery can be achieved by more straightforward management actions.

\section{RESEARCH PRIORITIES AND KNOWLEDGE GAPS}

The recent eggs and larvae surveys conducted within the Turkish Exclusive Economical Zone confirmed limitations on our understanding of the post-collapse characteristics of the anchovy stock behavior (Gucu et al., 2017). Generally speaking, fisheries science and biological oceanography pursue in the Black Sea independently from the progress made in understanding lower trophic food web dynamics and transfering knowledge from other disciplines. However, the current Black Sea recovery and restoration problems require building bridges across scientific and management barriers through better science communication between scientists, key stakeholders, and the community by efficient coordination between science, policy, and practice.

The Black Sea scientific community has a lot more to do for achieving a better understanding of the way in which cumulative effects of multiple stressors keep modulating overall ecosystem functioning. In spite of reduction in eutrophication and weakening of jelly and fish predation pressures in the ecosystem, there is no sign of an appreciable ecosystem rehabilitation. One explanation is the irriversibility of the present ecosystem state developed following the regime shift of the early 1990s. There is a major knowledge gap on how and when the current state of ecosystem may settle into an alternative ecologically more desirable equilibrium state. Its assessment on quantitative grounds is of crucial importance in terms of developing management strategies.

Recovery of major fish stocks and management of existing stocks under the pressures by multiple stressors appears to be a challenging task. It requires determining likely recovery paths of the ecosystem under different combinations of pressures, and its understanding demands an extensive scientific research. A part of this general problem concerns an estimation of the energy diverted to the jellies and opportunistic species under different climatic and environmental conditions.

The lack of systematic time series measurements hinders assessing current status of acidification and its vertical structure in the aerobic part of the water column. The current ecosystem models are presently not coupled with the carbonate chemistry to investigate the acidification problem under synergistic effects of climate change and eutrophication. How the Black Sea ecosystem might respond to future changes in climate in combination with other drivers appears to depend on characteristics of other stressors (Niiranen et al., 2013). Preliminary studies have been conducted by Cannaby et al. (2015) but a deeper analysis under different scenarios of stressor combinations (different combinations of fishing and nutrient load management scenarios) are worthwhile to perform.

Recently, there is a growing evidence in the literature that small mesoscale and submesoscale flow features may have critical impacts on the food web structures. This implies integrating small scale physics more accurately by means of fine resolution observations and mass balance food web models that are frequently used as a fishery management tool. Another important research subject is to improve model uncertainties and optimize the trade-offs between complex and simple models. Increasingly 
complex models provide detailed simulations but require large datasets for model setup/validation and generate outputs which are difficult to synthesize and interpret. In addition, a holistic modeling approach (ecological + socio-economic models) is an enormous undertaken due to insufficient knowledge of the system. On the other hand, simple models due to generalization of processes or coarse spatial/temporal resolutions may fail to capture important ecosystem features. An important criterion for these models is to be able to come up with solutions that do not require complicated and expensive implementation, prohibitive data requirements, and long-term applications.

In general, scientific research was not encouraged by state agencies in the past due to their reluctance for investing onto oceanographic research programs, data sharing and pooling, and it is not clear how much research can be realized under present economical capabilities and priorities of the riparian countries. But, as implied by the present analysis, performing an intensive ecosystem level research is absolutely essential to build up a basis for planning and realization of ecosystembased adaptive management strategies. Because of the regional differences in ecosystem characteristics, these studies may be partly conducted as the region specific. The current experience also suggests enormous difficulties to be faced along the road. For example, in spite of more advanced research capacity and broader scientific basis, the management strategies developed in the Baltic Sea was found to be not accurate enough to exploit resources and the environment in an adaptive, sustainable manner. One particular difficulty was associated with the nonlinearly interacting effects of ocean acidification, eutrophication and climate change (Jutterström et al., 2014).

\section{CONCLUSIONS}

The present Black Sea ecosystem undergoes a slow recovery once perturbed and degraded since the 1970s. However, the fishery reveals no sign of recovery after its collapse at the end of 1980s. At present, nearly all commercially important fish stocks have been severely depleted due to decades of unsustainable fishing efforts resulting from excessive fishing capacity and inappropriate fishing practices. The present Black Sea fishery is limited to anchovy and even this economically undesirable, low-income fishery is concentrated only to its southeastern part. The rest of the sea does not support much fish. This is a unique and devastating case among the large marine ecosystems

\section{REFERENCES}

Akoglu, E., Salihoglu, B., Libralato, S., Oguz, T., and Solidoro, C. (2014). An indicator-based evaluation of Black Sea food web dynamics during 1960-2000. J. Mar. Syst. 134, 113-125. doi: 10.1016/j.jmarsys.2014.02.010

Arai, M. N. (2001). Pelagic coelenterates and eutrophication: a review. Hydrobiologia 451, 69-87. doi: 10.1023/A:1011840123140

Arashkevich, E. G., Stefanova, K., Bandel, V., Siokou, I., Kurt, T. T., Orek, Y. A., et al. (2014). Mesozooplankton in the open Black Sea: regional and seasonal characteristics. J. Mar. Syst. 135, 81-96. doi: 10.1016/j.jmarsys.2013. 07.011 in the world and represents an almost collapsed ecosystem with a size of $\sim 400,000 \mathrm{~km}^{2}$, not a small bay or coastal ecosystem.

In addition to the inappropriate management measures, the lack of recovery may also be related to the impacts of external pressures on the food web functioning. These pressures impose negative effects on the recovery and may make the system resilient to switch to a new alternative stable (healthy) state. Therefore, the overfishing problem is more than setting quotas and reducing the fleet capacity and demands a holistic approach by considering two-way interactions between higher and lower trophic levels and biogeochemical processes. Clearly, first thing to do is to reduce the fleet capacity to a level that maintains a balance between available fishing effort and resources, to set catch limits for fish stocks in consistent with scientific advice, to ban fisheries for particular stocks and/or regions. However, the management strategy needs to include additionally ecosystem-level planning and ecosystem-based integrated assessments. This approach involves recognizing and addressing interactions among different spatial and temporal scales, within and among ecological and social systems, and among stakeholder groups. It also needs an efficient coordination between science, policy, and practice for addressing key research needs, building interdisciplinary scientific capacity, and synthesizing and communicating scientific knowledge to policy makers, managers, and other stakeholders. Implementation of ecosystem-based management strategy requires operational tools that are developed collaboratively by scientists and managers. For all these efforts, scientific advice is of critical importance and the Black Sea community may benefit from the experience and know-how developed in the Baltic Sea due to their close similarities.

\section{AUTHOR CONTRIBUTIONS}

The author confirms being the sole contributor of this work and approved it for publication.

\section{ACKNOWLEDGMENTS}

This study was supported in part by DEKOSIM (BAP- 08-11DPT2012K120880) Project funded by the Turkish Ministry of Development. We thank referees for their constructive criticisms and useful suggestions.
Artioli, Y., Friedrich, J., Gilbert, A. J., and Pollehne, F. (2008). Nutrient budgets for European seas: a measure of the effectiveness of nutrient reduction policies. Mar. Pollut. Bull. 56, 1609-1617. doi: 10.1016/j.marpolbul.2008.05.027

Belokopytov, V. N. (2011). Interannual variations of the renewal of waters of the cold intermediate layer in the Black Sea for the last decades. Phys. Oceanogr. 20, 347-355, doi: 10.1007/s11110-011-9090-x

Boldt, J. L., Martone, R., Samhouri, J., Perry, R. I., Itoh, S., Chung, I. K., et al. (2014). Developing ecosystem indicators for responses to multiple stressors. Oceanography 27, 116-133. doi: 10.5670/oceanog.2014.91

Bopp, L., Resplandy, L., Orr, J. C., Doney, S. C., Dunne, J. P., Gehlen, M., et al. (2013). Multiple stressors of ocean ecosystems in the 21st 
century: projections with CMIP5 models. Biogeosciences 10, 6225-6245. doi: 10.5194/bg-10-6225-2013

Brotz, L., Cheung, W. W. L., Kleisner, K., Pakhomov, E., and Pauly, D. (2012). Increasing jellyfish populations: trends in large marine ecosystems. Hydrobiologia 690, 3-20. doi: 10.1007/s10750-0121039-7

BSC (2009). State of the Environment of the Black Sea (2001-2006/7), Publications of the Commission on the Protection of the Black Sea Against Pollution (BSC) 2008-3, ed T. Oguz, Istanbul, 421.

Cannaby, H., Fach, B. A., Arkin, S. S., and Salihoglu, B. (2015). Climatic controls on biophysical interactions in the Black Sea under present day conditions and a potential future (A1B) climate scenario. J. Mar. Syst. 141, 149-166. doi: 10.1016/j.jmarsys.2014.08.005

Daskalov, G. M., Grishin, A. N., Rodianov, S., and Mihneva, V. (2007). Trophic cascades triggered by overfishing reveal possible mechanisms of ecosystem regime shifts. Proc. Natl. Acad. Sci. U.S.A. 104, 10518-10523, doi: 10.1073/pnas.0701100104

Doney, S. C., Ruckelshaus, M., Duffy, J. E., Barry, J. P., Chan, F., English, C. A., et al. (2012). Climate change impacts on marine ecosystems. Annu. Rev. Mar. Sci. 4, 11-37. doi: 10.1146/annurev-marine-041911111611

FAO (2016). The State of Mediterranean and Black Sea Fisheries. General Fisheries Commission for the Mediterranean. Rome.

Gregoire, M., and Friedrich, J. (2004). Nitrogen budget of the North-Western Black Sea shelf as inferred from modeling studies and in-situ benthic measurements. Mar. Ecol. Prog. Ser. 270, 15-39. doi: 10.3354/meps270015

Gucu, A. C., Genç, Y., Dağtekin, M., Sakınan, S., Ak, O., Ok, M., et al. (2017). On black sea anchovy and its fishery. Rev. Fish. Sci. Aquacult. 25, 230-244. doi: 10.1080/23308249.2016.1276152

Gucu, A. C., Inanmaz, O., Ok, M., and Sakınan, S. (2016). Recent changes in the spawning grounds of Black Sea anchovy, Engraulis encrasicolus. Fish. Oceanogr. 25, 67-84. doi: 10.1111/fog. 12135

Hoegh-Guldberg, O., and Bruno, J. F. (2010). The impact of climate change on the world's marine ecosystems. Science 328, 1523-1528. doi: 10.1126/science.1189930

Jutterström, S., Andersson, H. C., Omstedt, A., and Malmaeus, J. M. (2014). Multiple stressors threatening the future of the Baltic SeaKattegat marine ecosystem: implications for policy and management actions. Mar. Pollut. Bull. 86, 468-480. doi: 10.1016/j.marpolbul.2014. 06.027

Kideys, A. E., Gordina, A. D., Bingel, F., and Niermann, U. (1999). The effect of environmental conditions on the distribution of eggs and larvae of anchovy (Engraulis encrasicolus L.) in the Black sea. ICES J. Mar. Sci. 56, 58-64. doi: $10.1006 /$ jmsc. 1999.0605

Knudsen, S., and Toje, H. (2008). Post-Soviet transformations in Russian and Ukrainian Black Sea fisheries: socio-economic dynamics and property relations. Southeast Eur. Black Sea Stud. 8, 17-32. doi: 10.1080/146838508020 12149

Kovalev, A. V., and Piontkovski, S. A. (1998). Interannual changes in the biomass of the Black Sea gelatinous zooplankton. J. Plank. Res. 20, 1377-1385. doi: 10.1093/plankt/20.7.1377

Kubryakov, A. A., Stanichny, S. V., Zatsepin, A. G., and Kremenetskiy, V. V. (2016). Long-term variations of the Black Sea dynamics and their impact on the marine ecosystem. J. Mar. Syst. 163, 80-94. doi: 10.1016/j.jmarsys.2016. 06.006

Llope, M., Daskalov, G. M., Rouyer, T. A., Mihneva, V., Chan, K., Grishin, A. N., et al. (2011). Overfishing of top predators eroded the resilience of the Black Sea system regardless of the climate and anthropogenic conditions. Glob. Chang. Biol. 17, 1251-1265. doi: 10.1111/j.1365-2486.2010. 02331.x

Mahadevan, A. (2016). Physics on primary productivity of plankton. Annu. Rev. Mar. Sci. 8, 17.1-17.24. doi: 10.1146/annurev-marine-010814015912

Medinets, S., and Medinets, V. (2012). Investigations of atmospheric wet and dry nutrient deposition to marine surface in Western part of the Black Sea. Turkish J. Fish. Aquat. Sci. 12, 497-505. doi: 10.4194/1303-2712-v12_2_42

Mee, L. D. (2006). Reviving dead zones. Sci. Am. 295, 54-61. doi: $10.1038 /$ scientificamerican $1106-78$
Mikaelyan, A. S., Zatsepin, A. G., and Chasovnikov, V. K., (2013). Long-term changes in nutrient supply of phytoplankton growth in the Black Sea. J. Mar. Syst. 117, 53-64. doi: 10.1016/j.jmarsys.2013. 02.012

Mutlu, E. (2009). Recent distribution and size structure of gelatinous organisms in the southern Black Sea and their interactions with fish catches. Mar. Biol. 156, 935-957. doi: 10.1007/s00227-009-1139-8

Niermann, U., Bingel, F., Gorban, A., Gordina, A. D., Gücü, A. C., Kideys, A. E., et al. (1994). 9. Distribution of anchovy eggs and larvae (Engraulis encrasicolus Cuv.) in the Black Sea in 1991-1992. ICES J. Mar. Sci. 51, 395-406. doi: $10.1006 /$ jmsc. 1994.1041

Niiranen, S., Yletyinen, J., Tomczak, M. T., Blenckner, T., Hjerne, O., MacKenzie, B., et al. (2013). Combined effects of global climate change and regional ecosystem drivers on an exploited marine food web. Glob. Chang. Biol. 19, 3327-3342, doi: $10.1111 / \mathrm{gcb} .12309$

Oguz, T., Akoglu, E., and Salihoglu, B. (2012a). Current state of overfishing and its regional differences in the Black Sea. Ocean Coast. Manage. 58, 47-56. doi: 10.1016/j.ocecoaman.2011.12.013

Oguz, T., and Fach, B., and, Salihoglu, B. (2008). Invasion dynamics of the alien ctenophore Mnemiopsis leidyi and its impact on anchovy collapse in the Black Sea. J. Plankton Res. 30, 1385-1397. doi: 10.1093/plankt/ fbn094

Oguz, T., Dippner, J. W., and Kaymaz, Z. (2006). Climatic regulation of the Black Sea hydro-meteorological and ecological properties at interannual-todecadal time scales. J. Mar. Syst. 60, 235-254. doi: 10.1016/j.jmarsys.2005. 11.011

Oguz, T., and Gilbert, D. (2007). Abrupt transitions of the top-down controlled Black Sea pelagic ecosystem during 1960-2000: evidence for regime shifts under strong fishery exploitation and nutrient enrichment modulated by climateinduced variations. Deep Sea Res. I 54, 220-242. doi: 10.1016/j.dsr.2006. 09.010

Oguz, T., Salihoglu, B., Moncheva, S., and Abaza, V. (2012b). Regional peculiarities of community-wide trophic cascades in strongly degraded Black Sea food web. J. Plankton Res. 34, 338-343. doi: 10.1093/plankt/ fbs002

Oguz, T., and Velikova, V. (2010). Abrupt transition of the northwestern Black Sea shelf ecosystem from a eutrophic to an alternative pristine state. Mar. Ecol. Prog. Ser. 405, 231-242. doi: 10.3354/meps08538

Piotukh, V. B., Zatsepin, A. G., Kazmin, A. S., and Yakubenko, V. G. (2011). Impact of the winter cooling on the variability of the thermohaline characteristics of the active layer in the Black Sea. Oceanology 51, 221-230. doi: 10.1134/S0001437011020123

Poloczanska, E. S., Brown, J. C., Sydeman, W. J., Kiessling,W., Schoeman, D. S., Moore, P. J., et al. (2013). Global imprint of climate change on marine life. Nat. Clim. Change 3, 919-925, doi: 10.1038/nclimate1958

Prodanov, K., Mikhaylov, K., Daskalov, G., Maxim, K., Ozdamar, E., Shlyakhov, V., et al. (1997). Environmental management of fish resources in the Black Sea and their rational exploitation. Gen. Fish. Counc. Mediterr. Stud. Rev. 68, $1-178$

Purcell, J. E., Shiganova, T. A., Decker, M. B., and Houde, E. D. (2001). The ctenophore Mnemiopsis in native and exotic habitats: U.S. estuaries versus the Black Sea basin. Hydrobiologia 451, 145-176. doi: 10.1023/A:10118266 18539

Rayner, N. A., Parker, D. E., Horton, E. B., Folland, C. K., Alexander, L. V., Rowell, D. P., et al. (2003). Global analyses of sea surface temperature, sea ice, and night marine air temperature since the late nineteenth century. J. Geophys. Res. 108, 4407. doi: $10.1029 / 2002 \mathrm{jd} 002670$

Shiganova, T. A., Legendre, L., Kazmin, A. S., and Nival, P. (2014). Interactions between invasive ctenophores in the Black Sea: assessment of control mechanisms based on long-term observations. Mar. Ecol. Prog. Ser. 507, 111-123. doi: $10.3354 /$ meps 10806

Shlyakhov, V. A., and Daskalov, G. M. (2009). The State of Marine Living Resources. State of the Environment of the Black Sea (2001-2006/7). The Commission on the Protection of the Black Sea Against Pollution publication, $272-295$

STECF (2015). Scientific, Technical and Economic Committee for Fisheries (STECF) - Black Sea Assessments (STECF-15-16). EUR 27517 EN, JRC 98095. Luxembourg: Publications Office of the European Union. 
Tugrul, S., Murray, J. W., Friederich, G. E., and Salihoğlu, I. (2014). Spatial and temporal variability in the chemical properties of the oxic and suboxic layers of the Black Sea. J. Mar. Syst. 135, 29-43. doi: 10.1016/j.jmarsys.2013.09.008

Vinogradov, M. E., Lebedeva, L. P., Anokhina, L. L., Vinogradov, G. M., Kulagin, D. N., Lukasheva, T. A., et al. (2011). Interannual variability of the zooplankton on the shelf of the Northeastern Black Sea in the autumn period. Oceanology 51, 814-825. doi: 10.1134/S0001437011050201

Vinogradov, M. E., Shushkina, E. A., Anokhina, L. L., Vostokov, S. V., Kucheruk, N. V., and Lukashova, T. A. (2000). Mass development of the ctenophore Beroe ovata Eschscoltz near the northeastern coast of the Black Sea. Oceanology 40, $52-55$.
Conflict of Interest Statement: The author declares that the research was conducted in the absence of any commercial or financial relationships that could be construed as a potential conflict of interest.

Copyright (c) 2017 Oguz. This is an open-access article distributed under the terms of the Creative Commons Attribution License (CC BY). The use, distribution or reproduction in other forums is permitted, provided the original author(s) or licensor are credited and that the original publication in this journal is cited, in accordance with accepted academic practice. No use distribution or reproduction is permitted which does not comply with these terms. 